\title{
Gastric glomus tumor: report of one case and review
}

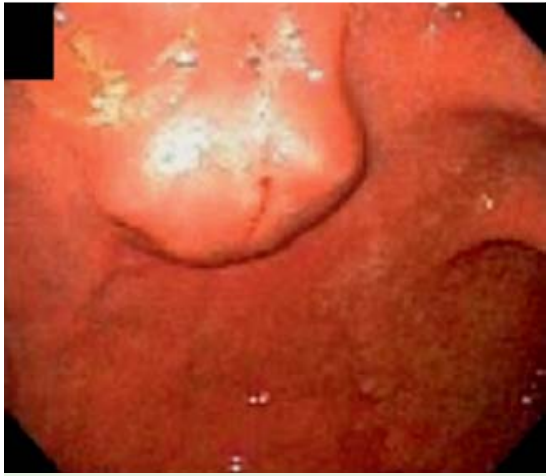

Fig. 1 Endoscopic image of a well-defined submucosal tumor with normal overlying mucosa.

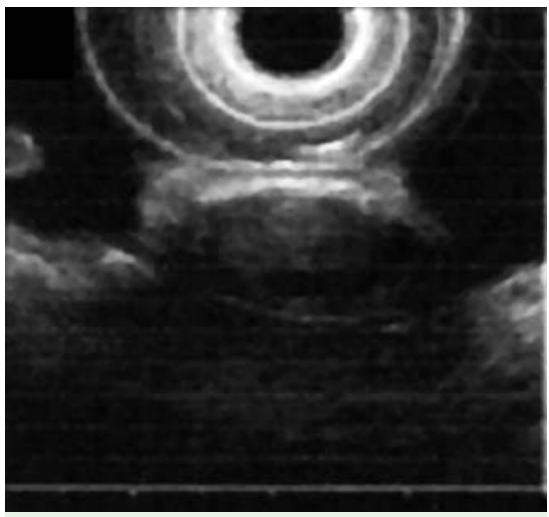

Fig. 2 Endoscopic ultrasound showing a tumor arising from the muscular layer.

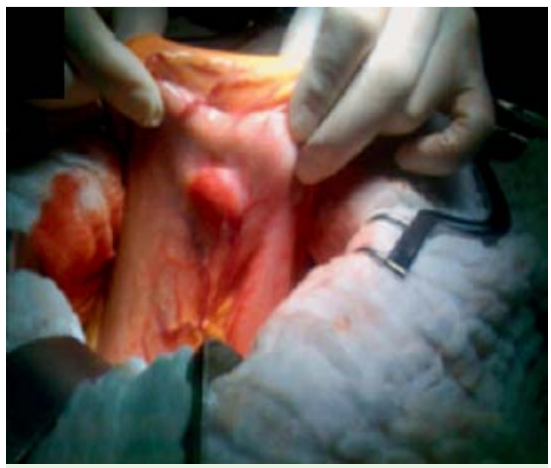

Fig. 3 Findings at surgery. A rounded tumor in the anterior distal gastric body, with well defined borders. A local excision was performed.
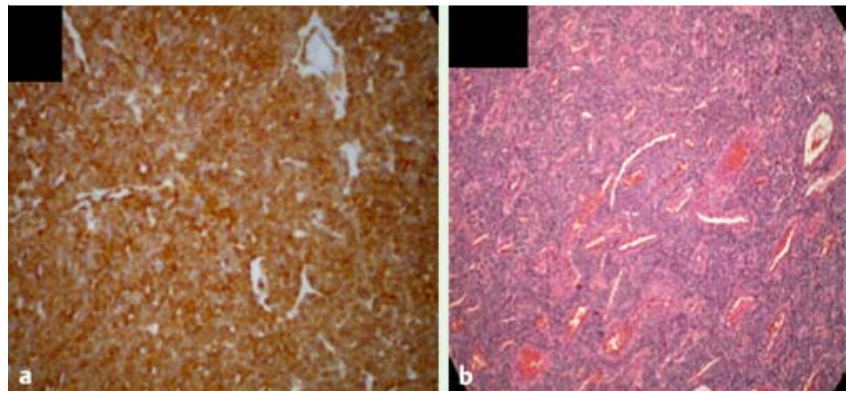

Fig. 4 a Histopathology showing positive staining for smooth muscle actin. b Hematoxylin and eosin stain; low magnification. Nests of glomus cells surrounding capillarysize vessels.

A healthy 26-year-old woman presented with a year of intermittent epigastric pain but no other symptoms. Upper gastrointestinal endoscopy showed, on the anterior wall of the gastric body, a submucosal, elevated, well-defined lesion measuring $3 \mathrm{~cm}$ in diameter, with normal overlying mucosa ( $\bullet$ Fig. 1).

Endoscopic ultrasonography showed a hypoechoic lesion arising from the muscularis propria, without deep involvement ( Fig. 2), compatible with a gastrointestinal stromal tumor (GIST).

The patient was operated on. A well-defined 2-cm tumor, without serosal involvement, was found on the anterior wall of the gastric body. A partial gastrectomy was done with 1-cm margins ( $\bullet$ Fig. 3). The patient was discharged without problems.

The biopsy showed in the muscularis propria a well-defined stromal tumor made of vascular structures, covered by a single layer of endothelial cells, and with dense cellular proliferation around the vascular structures, with low mitotic rate (one or two mitoses per 50 high-power fields) and without necrosis. Immunohistochemical staining was positive for smooth muscle actin. The conclusion was that it was a glomangioma ( $\bullet$ Fig. 4a,b).

Glomus tumors are rare. Nearly $75 \%$ of glomus tumors are localized in the hands, under the nails [1]. They originate from the normal myoarterial apparatus and are constituted by an afferent arteriole and vascular channels with endothelial cells, surrounded by cuboidal cells [2]. Just $2 \%$ of benign gastrointestinal tumors are vascular tumors; most are glomus tumors [3]. The majority are asymptomatic, and the diagnosis is incidental; upper gastrointestinal bleeding and ulcerous syndrome are the most frequent symptoms. Glomus tumors have a female predominance $(2.5: 1)$. The majority are benign and single, but the malignant potential is unpredictable $[4,5]$. The peak incidence of glomus tumors is in the sixth decade of life. Diagnosis is generally done after surgery. During endoscopy, a submucosal mass similar to smooth muscle is generally found. Computed tomography (CT) shows an enhanced pattern with contrast. Histological studies show a low mitotic rate, positive staining for actin and calponin, and negative for c-kit, chromogranin and common leucocyte antigen, which differentiate GIST, carcinoids, and lymphoma respectively, the three differential diagnoses. The management is surgical resection for final diagnosis and treatment [5].

Endoscopy_UCTN_Code_CCL_1AB_2AD_3AB

Competing interests: None 
F. Orellana ${ }^{1,2,3}$, C. Onetto ${ }^{2}$, P. Balbontín $^{1,3}$, D. Videla ${ }^{1,2}$, L. Manriquez ${ }^{1,2}$, R. Plass ${ }^{1,3}$, R. Araya ${ }^{3}$, R. Sepúlveda ${ }^{1,2}$, R. Saenz ${ }^{4}$, H. Ríos ${ }^{1,2}$

1 Department of Surgery, Hospital Militar de Santiago, Santiago, Chile

2 Department of Surgery, Universidad de Los Andes, Santiago, Chile

3 Department of Gastroenterology, Hospital Militar de Santiago, Santiago, Chile

4 Department of Gastroenterology, Clínica Alemana de Santiago, Santiago, Chile

\section{References}

1 Agawa H, Matsushita M, Nishio A, Takakuwa $H$. Gastric glomus tumor. Gastrointest Endosc 2002; 56: 903

2 Maehara Lde S, Ohe EM, Enokihara MY et al. Diagnosis of glomus tumor by nail bed and matrix dermoscopy. An Bras Dermatol 2010; 85: 236-238

3 Fabiani P, Benizri E, Michiels JF et al. A new case of gastric glomangioma. Gastroenterol Clin Biol 1993; 17: 974-975

4 Alempijevic T, Knezevic S, Knezevic D et al. Gastric multicentric glomangioma: a case report of this rare cause of abdominal pain. Med Sci Monit 2008; 14: CS5 - CS8

5 Lorber J, Kalish J, Farraye FA et al. Glomus tumor of the gastric antrum: case report. Curr Surg 2005; 62: 436-438

\section{Bibliography}

DOI $10.1055 / \mathrm{s}-0030-1256041$

Endoscopy 2011; 43: E71 - E72

(c) Georg Thieme Verlag KG Stuttgart · New York . ISSN 0013-726X

\section{Corresponding author}

Franco Orellana Gárate, MD

Department of Surgery

Hospital Militar de Santiago

Avenida Larraín 9100

La Reina

Santiago

Región Metropolitana 7560872

Chile

Fax: +56-2-8811374

fforella@gmail.com 